\title{
RELATO DE MOBILIDADE ACADÊMICA NA INSTITUIÇÃO SAINT MARY'S UNIVERSITY EM HALIFAX, CANADÁ
}

\author{
Rafael Caixeta Vieira Araujo \\ Graduando em Geografia - Universidade Federal de Uberlândia \\ ra.fass@hotmail.com
}

\section{Introdução}

Desde muito novo, realizar uma mobilidade internacional - também conhecida como intercâmbio - que me possibilitaria conhecer um novo país, estar em contato com diferentes culturas e praticar um novo idioma foi um desejo que sempre tive. Contudo, a oportunidade para realizá-lo apenas surgiu após meu ingresso na universidade.

No começo de 2017 dei início ao curso de Geografia na Universidade Federal de Uberlândia (UFU). Logo ao fim de meu segundo semestre acadêmico comecei a procurar por bolsas de intercâmbio para realizar um período de meus estudos universitários em alguma instituição parceira em outro país. Acredito que realizar um intercâmbio acadêmico durante a graduação permite também conhecer diferentes abordagens na área de atuação do indivíduo, assim como novas metodologias, tanto de ensino quanto práticas. Outro ponto positivo é possibilitar a criação de uma rede de contatos e o possível estabelecimento de parcerias entre, não somente aluno e professor, mas também entre os cursos de ambas universidades.

Encontrei em novembro de 2017, uma oportunidade que parecia ideal para a realização de meus objetivos, a bolsa de estudos oferecida pelo governo do Canadá, intitulada Emerging Leaders in the Americas Program (ELAP). O programa busca fortalecer a formação de capital humano e os laços acadêmicos entre instituições de ensino canadenses e da América Latina e do Caribe através de intercâmbios de até 6 meses em universidades do país, com enfoque especial em questões como boa governança, direitos humanos, meio ambiente, diversidade e respeito aos povos indígenas. Além destas, que foram características que despertaram meu interesse em me candidatar para esta bolsa, estava a possibilidade de conseguir financiamento para meus estudos, uma vez que sem este apoio financeiro, uma mobilidade desta magnitude para um país com moeda mais forte que a brasileira se tornaria inviável.

Recebido em 12/2018 / Aprovado para publicação em 26/04/2019.

OBSERVATORIUM: Revista Eletrônica de Geografia, v. 9, n. 3, p. 347-356. set./dez. 2018. 
Entre a data em que tomei conhecimento da bolsa e o fim do período de inscrição, que começou em fevereiro e terminou em abril de 2018, tive aproximadamente seis meses para me preparar. Ao final de junho do mesmo ano, recebi a notícia de que obtive sucesso em minha candidatura, o que me possibilitou passar quatro meses na instituição de ensino Saint Mary's University (Universidade Saint Mary's ou SMU), parceira da UFU que possuía um interessante programa de Geografia, em Halifax.

O objetivo deste texto é relatar brevemente minha experiência de mobilidade acadêmica no Canadá, explicando de forma resumida o Programa através do qual a mobilidade foi realizada (ELAP) e minha experiência ao longo de um semestre acadêmico cursando disciplinas de Geografia na Universidade Saint Mary’s, em Halifax.

\section{Emerging Leaders in the Americas Program (ELAP)}

O ELAP, criado em 2009, é um programa de bolsas do Department of Foreign Affairs, Trade and Development (DFATD) do Canadá. É destinado a estudantes da América Latina e do Caribe a nível de graduação e pós-graduação para a realização de estudos ou pesquisas no país por até seis meses. A cada ano são disponibilizadas mais de 400 bolsas de estudo ${ }^{2}$.

O valor da bolsa varia conforme o nível de formação do candidato e o tempo de permanência desejado. A quantia para graduandos ou pós-graduandos em intercâmbios de até quatro meses é de 7200 dólares canadenses, o que à época equivalia a cerca de $\mathrm{R} \$ 21.600$, que objetivam cobrir as despesas com translado, habitação e custo de vida durante a estadia no país. Para um período entre cinco e seis meses, oferecida apenas a pós-graduandos, o valor é de 9700 dólares canadenses ou R $\$ 29.100$. A inscrição no programa é feita pela universidade canadense, responsável por enviar a documentação encaminhada pelos candidatos para o DFATD. Os editais são disponibilizados nos primeiros meses do ano e o período de inscrição varia a cada edição. Quando me candidatei, em 2018, as inscrições se estenderam até dia 17 de abril.

\section{Processo de candidatura}

Em minha busca por oportunidades que me permitiriam realizar o intercâmbio que há muito almejava, descobri, ao final de 2017, o programa ELAP, quando o edital daquele ano já estava fechado e ainda não sabia da data de lançamento do edital seguinte. Familiarizar-me 
com a bolsa e o processo de candidatura com antecedência me permitiu planejar-me e traçar um plano de ação, com tempo hábil, para garantir que eu me informasse junto às universidades e completasse todos os requisitos do programa.

O programa exige prévio convênio ou acordos de parceria entre as universidades brasileiras e canadenses (que, no caso da UFU, exigiu esforços prévios da Diretoria de Relações Internacionais e Interinstitucionais (DRII) para checar a viabilidade e por fim firmar novos acordos com outras universidades canadenses onde o idioma de instrução fosse o inglês (o qual eu detinha proficiência atestada pelo exame TOEFL ITP). Por fim, a UFU renovou um convênio já existente com a Universidade Saint Mary's, onde existe um curso de graduação em Geografia.

Em fevereiro de 2018 o edital foi aberto, com previsão de fechamento em meados de abril. Em razão do início do semestre acadêmico ter se dado em março, não havia tempo hábil para que a UFU lançasse um edital interno de seleção para participação no ELAP. Desta forma, foi-me informado que eu deveria buscar a aprovação e autorização de meu intercâmbio, necessária para o envio de documentação para a SMU no colegiado do curso de Geografia da UFU. Para isso, foi necessário apresentar um plano de estudo com as disciplinas que gostaria de cursar, assim como uma carta de intenção e de recomendação - esta última escrita pelo Prof. Dr. Mirlei Fachini Vicente Pereira, também tutor do PET Geografia UFU explicando o objetivo do intercâmbio e de que forma ele contribuiria para minha formação acadêmica. É importante ressaltar a relevância de uma experiência acadêmica como esta, uma vez que permite conhecer novas abordagens, novas práticas e também metodologias de ensino na Geografia. Além disso possibilita também tentar estabelecer contatos e possíveis parcerias e colaborações que possam trazer frutos positivos para o curso de ambos países.

Após a aprovação, a documentação necessária foi enviada pela secretaria do curso à DRII, que por sua vez a enviou para a SMU, com quem havia renovado o acordo de cooperação - que seria a responsável por realizar minha inscrição.

O resultado positivo, com a aprovação da bolsa (sem a qual não poderia realizar o intercâmbio almejado) foi dado no dia 28 de junho. Havia me planejado para, caso fosse aprovado, começar meus estudos em setembro daquele ano. Isso significava que teria cerca de dois meses entre a data da aprovação e do início das aulas para conseguir tudo o que precisava a fim de dar início aos meus estudos no Canadá, entre os quais estavam conseguir o visto, acomodação e passagens aéreas (a bolsa só é disponibilizada assim que os alunos chegam ao Canadá). Tive ajuda da universidade com orientações acerca de opções de habitação, uma vez 
que não iria morar na residência estudantil, em função do alto valor e pouca disponibilidade. Por fim, cheguei ao Canadá no dia 30 de agosto de 2018.

\section{Universidade Saint Mary's: Recepção, campus, atividades e serviços oferecidos.}

A universidade, fundada em 1802, é uma instituição pública de ensino superior e conta com cerca de 7000 alunos de graduação e pós-graduação de diversas partes do mundo, com aproximadamente $29 \%$ de seus estudantes vindo de outros 118 países. Saint Mary’s University conta com 44 cursos de graduação e 26 programas de pós-graduação, incluindo mestrado em Geografia ${ }^{3}$.

A universidade conta com três residências estudantis anexas ao campus, diversos prédios acadêmicos, um campo de futebol americano, academia, quadras poliesportivas, biblioteca, livraria, cafeterias e um bar/balada, onde eram realizadas festas organizadas pela associação estudantil. A instituição conta também com laboratórios, centros de idiomas e escrita, além de vários computadores espalhados pelo campus aos quais os alunos podem acessar utilizando o $\log$-in fornecido pela universidade. Os discentes e pesquisadores do programa de Geografia contam também com um laboratório próprio com mais de 20 computadores e impressão gratuita.

As aulas na universidade apenas começariam no dia 5 de setembro, contudo a universidade havia preparado atividades de recepção para os estudantes internacionais e calouros a partir do dia 31 de agosto. Dentre as atividades programadas, havia uma apresentação da instituição, assim como uma tradicional cerimônia de inauguração do ano letivo, feiras acadêmicas informando acerca de necessidades estudantis (como seguro saúde e passe de ônibus), além de atividades recreativas e outras oportunidades na universidade. Foram feitas também gincanas de interação entre os novatos, e, deste modo, foram nestas atividades que conheci a maioria dos novos amigos que fiz no Canadá. Excursões gratuitas para pontos turísticos nas redondezas também foram oferecidas. Em uma delas tive a oportunidade de visitar um dos pontos mais conhecidos e fotografados das províncias canadenses do Atlântico: Peggy's Cove, uma antiga vila de pescadores, e seu famoso farol.

Quanto às atividades extra-curriculares nas quais os estudantes podiam se engajar, havia o torneio amistoso esportivo conhecido como "Intramurals", com diversas modalidades, como voleibol, futebol, frisbee, softbol e badminton. Os alunos também podiam tentar vagas nos times competitivos da universidade nessas modalidades e também em outras como tênis e hockey - que é para os canadenses o que o futebol é para os brasileiros. Havia 
também grupos, clubes e organizações com os mais diversos objetivos aos quais os discentes poderiam se afiliar.

\section{Universidade Saint Mary's: as aulas no curso de Geografia}

Existem diferentes tipos de intercâmbios acadêmicos, desde pesquisa a cursos curtos. $\mathrm{Eu}$, no entanto, fui realizar um período letivo do curso de bacharelado em Geografia na Universidade Saint Mary's. Deste modo, cursei disciplinas com os demais alunos do curso, podendo validá-las na UFU após meu retorno ao Brasil. Em meu período em Halifax, matriculei-me em três disciplinas do curso de Geografia, além de Francês Intermediário, ao qual me inscrevi para continuar a aprender o idioma.

A abordagem de cada professor variava significativamente. As disciplinas do curso de Geografia que cursei na SMU foram as seguintes:

1 - Mudanças Climáticas: Impacto, Vulnerabilidade e Adaptação;

2 - Geografia da África Subsaariana;

3 - Perspectivas Globais sobre a Terra e a Vida.

Cada matéria era lecionada duas vezes por semana e cada encontro tinha duração de uma hora e quinze minutos. O material utilizado também variava. No curso de Geografia da UFU é comum que o professor de uma disciplina designe a cada aula uma leitura diferente, pertinente ao assunto a ser discutido, frequentemente de fontes e autores variados. Em Geografia da África Subsaariana e Perspectivas Globais sobre a Terra e a Vida, no entanto, fora empregado um único livro em cada que serviu de base para todo o conteúdo das disciplinas (cada um custando aproximadamente 100 dólares canadenses ou R $\$ 300,00$ ), leituras essas por vezes complementadas com artigos extras indicados pelos professores. A matéria de Mudanças Climáticas, por outro lado, utilizava relatórios governamentais ou de agências de monitoramento e pesquisa climáticas, disponibilizado pelo professor no site da universidade, e sem custos. Por sua vez, o material utilizado nas aulas de francês foi preparado pela própria professora e sua impressão custava menos de 10 dólares, cerca de $\mathrm{R} \$ 30,00$.

O sistema de pontuação da universidade era diferente do brasileiro (que normalmente varia numa escala numérica), enquanto que canadense é realizado por conceitos, em que A+é a maior nota, A a segunda maior, A- a terceira e assim sucessivamente. 
O método de avaliação também variava, desde quizzes, discussões em sala, até provas e trabalhos de pesquisa. Este último foi realizado apenas na matéria Geografia da África Subsaariana. Nele era esperado que os alunos escolhessem um tema de pesquisa pertinente à disciplina, encontrassem artigos acadêmicos e outras fontes como referências bibliográficas e escrevessem um texto de pelo menos 10 páginas, a partir de modelo definido pela professora. No meu caso, pesquisei sobre mudanças climáticas e adaptação no Sahel Ocidental africano.

$\mathrm{Na}$ SMU existem pessoas e centros especializados em orientar os alunos em cada uma das etapas de pesquisa descritas acima: os bibliotecários - com quem se pode marcar reuniões - são responsáveis por ensinar a navegar os bancos de dados online e encontrar textos relevantes e o Centro de Escrita a ajustar o texto conforme a formatação adequada, além de auxiliar com a escrita acadêmica. Dessa forma, não se espera do professor um papel tão ativo no acompanhamento desses estágios de execução do trabalho, e sim opiniões acerca de seu conteúdo e das fontes já escolhidas. É notória também a velocidade com que os trabalhos e provas são corrigidos, muitas vezes sendo entregues na aula seguinte à realização ou entrega da avaliação (não demorando mais que uma semana e meia). De maneira geral, cada atividade vinha com comentários detalhados acerca dos pontos a serem melhorados.

A relação com os professores era relativamente próxima, tendo eles sido muito acessíveis sempre que precisei tirar dúvidas ou conversar acerca de qualquer outra questão. A interação com os colegas de classe, salvas exceções, era menos frequente. Sobre isso, avalio que algumas questões podem ter influenciado, como o fato de eu não ter conhecido os alunos desde os anos iniciais, por ter escolhido matérias de diferentes períodos (segundo meus interesses), bem como pela curta duração de cada aula (aspecto bastante diferente do curso que realizo na UFU). Assim, apesar de ter construído algumas amizades dentre os colegas que cursavam Geografia, convivi de forma mais intensa com os outros intercambistas, que havia conhecido na semana de recepção.

Perspectivas Globais sobre a Terra e a Vida era uma matéria lecionada para alunos do primeiro período. Seu foco era nas grandes regiões mundiais, suas características físicas, políticas e sociais. Cada região tinha um conjunto de aulas a ela dedicado, com um número de páginas de leitura do livro associado para cada uma. A professora se utilizava de vários slides, com mapas e texto, além de vídeos e notícias pertinentes (de modo geral uma aula expositiva). A disciplina visava apresentar um resumo das regiões do mundo hoje, sem, contudo, se aprofundar ou se deter por muito tempo nos temas discutidos. 
A professora de Geografia da África Subsaariana seguia um modelo de aula relativamente parecido com o descrito acima, fazendo uso de slides e de um livro base para a disciplina. Contudo, havia também aulas com estudos de caso sobre determinados temas, em que nos debruçávamos sobre suas questões com maior nível de detalhamento. A professora tinha extensa experiência sobre o continente (em especial o oeste africano que era sua especialidade de pesquisa, tendo viajado a muitos países da região diversas vezes).

Mudanças Climáticas: Impactos, Vulnerabilidade e Adaptação seguiu um modelo de aula expositiva relativamente semelhante às demais, com utilização de slides e vídeos ocasionais. No entanto, os textos utilizados mudavam a cada semana, sendo frequentemente relatórios governamentais ou de agências de monitoramento e pesquisa climáticas. Algo que diferenciou esta disciplina das demais foi o fato de os alunos trabalharem em grupos, e a cada semana cada um receberia um texto diferente em que um de seus membros deveria apresentar para o restante da turma. Após a apresentação, era feita uma discussão acerca das temáticas expostas.

As aulas de Francês Intermediário eram dinâmicas, talvez a mais dinâmica entre as disciplinas cursadas. A parte expositiva, com utilização de slides e apresentação das regras gramaticais era intercalada com frequentes atividades em que éramos incentivados a desenvolver a competência oral por meio de discussões, sendo divididos em grupos. A produção escrita também fazia parte de cada aula, além das avaliações que deveríamos entregar.

De maneira geral, penso que o período mais curto de cada aula faz com que o professor ou a professora não consigam tratar com grande nível de detalhamento cada assunto discutido. São disponibilizados muitos recursos, no entanto, como acesso a extenso banco de dados online, assim como vários outros conteúdos midiáticos apresentados pelos professores, para que os alunos possam investigar os assuntos de interesse e buscar informações adicionais por conta própria. Percebo que é esperado dos alunos nas universidades canadenses, ou pelo menos na Universidade Saint Mary's, um maior nível de independência para complementar e aprofundar a formação oferecida pela instituição de ensino.

\section{Sobre a cidade de Halifax}

Halifax é uma cidade costeira com pouco menos de 418.000 habitantes segundo a última estimativa ${ }^{4}$, capital da província da Nova Escócia, no leste do Canadá. É também a 
maior cidade das províncias do Atlântico, grupo que compreende, além da Nova Escócia, Terra Nova e Labrador, Nova Brunswick e Ilha do Príncipe Eduardo. Sua economia é muito influenciada por seu porto, sendo uma das principais entradas de mercadorias via marítima. É notável também a pesca, a exploração de madeira e a agricultura em sua economia.

É uma cidade com opções diversas de entretenimento e marcada pela vida universitária. O centro da cidade, além de possuir uma grande parte de seus prédios históricos, também conta com estruturas modernas, museus, galerias de arte, bares, restaurantes, uma arena poliesportiva e o porto de Halifax. É lá também que se encontram as fortificações na colina de Citadel Hill, monumento histórico do Canadá, que era responsável pela proteção do porto da cidade.

Halifax também possui um jardim botânico e alguns parques, como o parque Point Pleasant, ao sul da península e com vista para o oceano (o que eu mais frequentava).

A cidade foi também a porta de entrada de grande número de imigrantes no Canadá, especialmente os vindos da Europa, por ser uma cidade costeira com um grande porto. Possui o interessante Museu da Imigração, que conta a história e os processos pelos quais passavam os imigrantes ao entrar no Canadá.

O clima sofre grande influência marítima. Os acumulados de chuva são elevados e bem distribuídos ao longo do ano, seus verões são mornos e seus invernos não são tão frios, se comparado aos padrões canadenses de latitudes similares afastados da costa. Normalmente a ocorrência de neve se dá de novembro a abril, mas a cobertura de gelo não é constante, com frequentes degelos uma vez que os períodos frios são intercalados com temperaturas positivas.

Foi uma experiência interessante chegar ainda no verão (final de agosto), com temperaturas agradáveis e até mesmo certo calor e poder me preparar e me adaptar gradualmente ao frio à medida que o inverno ia se aproximando. Igualmente interessante foi poder acompanhar, em uma região famosa pela riqueza das cores de outono, a mudança da folhagem das árvores para tons de amarelo, laranja, vermelho e marrom antes de caírem à medida que a estação avançava. Ver a neve pela primeira vez e é um fenômeno deslumbrante. Tive sorte de não experimentar nenhum evento extremo como nevascas, mas devo reconhecer que a cidade está muito preparada para lidar com a neve em eventos de magnitudes normais, preparando ruas e calçadas com sal para que o gelo não se acumule. Todas as casas e estabelecimentos contam com sistema de aquecimento, portanto as temperaturas baixas se 
tornam bastante toleráveis a menos que a pessoa tenha que se expor ao frio e vento por longos períodos de tempo.

O custo de vida em Halifax não é tão alto quanto de outras capitais de província pelo país. Aluguei um quarto em uma casa onde morava com mais três canadenses, dois deles estudantes, o valor da conta de água, energia e aquecimento eram inclusos no valor do aluguel, que custava 600 dólares canadenses (CAD), ou aproximadamente R\$1800,00. Existem diversos mercados na cidade, e alguns oferecem descontos para estudantes em dias específicos, basta apresentar a carteirinha da universidade. É importante notar que o preço marcado na etiqueta dos produtos não equivale ao preço pago no final, sendo necessário adicionar o valor do imposto, que em Halifax é de 15\% (que não vem embutido no valor do produto) sobre tudo o que comprar. Isso também vale para o consumo em restaurantes, além da gorjeta para o atendente - prática comum e esperada de todos que consumem algo no estabelecimento. Uma surpresa positiva, no entanto, é água gratuita que você pode pedir em qualquer lugar, que é da torneira, porém potável.

\section{Considerações finais}

O intercâmbio que realizei entre o final de agosto e dezembro de 2018 foi uma experiência incomensurável, de crescimento não apenas acadêmico como também pessoal. Conheci pessoas e fiz amigos das mais diversas partes do mundo, imergi em uma nova cultura, conheci uma outra perspectiva e abordagem para a Geografia e um novo modelo de aulas, pratiquei um segundo idioma e estabeleci contatos que pretendo manter para o restante da vida.

Entre as maiores contribuições acadêmicas que a realização do intercâmbio me proporcionou foi o desenvolvimento de maior independência e assertividade ao trilhar meu caminho na academia e aprofundar meus estudos. Apesar de as aulas mais curtas dificultarem um maior aprofundamento nos assuntos discutidos em sala de aula, apresentaram-me recursos e técnicas aos quais poderia recorrer por contra própria para pesquisar o que me interessava e complementar o que julgava ser necessário.

Além disso, poder praticar diariamente a língua inglesa aumentou meu domínio e minha confiança ao me expressar escrita e oralmente, além aprimorar minha escrita acadêmica no idioma. Outrossim, as aulas me permitiram entrar em contato e conhecer novos 
estudiosos que produzem conhecimento nesta mesma língua, ampliando a gama de referências para futuros trabalhos e produções acadêmicas.

Os professores também apresentam aos alunos horizontes de possibilidade na pesquisa ao compartilharem suas experiências e sua trajetória na carreira acadêmica. Quanto a mim, demonstraram-se interessados em manter contato mesmo depois de voltar ao Brasil, assim como estabelecer parcerias quando possível, tornando-se uma importante rede de contatos.

Por fim, pretendo agora trazer o que aprendi e compartilhar com os demais colegas e professores de curso e, com sorte, estabelecer conexões que possam contribuir para nossa formação, assim como incentivar que mais pessoas busquem e alcancem experiências como esta.

\section{Notas}

\footnotetext{
${ }^{1}$ Discente do curso de Geografia, IG-UFU. Bolsista PET-MEC. Entre o fim de agosto e dezembro de 2018, foi bolsista do Programa ELAP, fornecida pelo governo do Canadá.

2 Para maiores informações, vide a página do Programa na internet: <https://www.scholarshipsbourses.gc.ca/scholarships-bourses/can/institutions/elap-pfla.aspx?lang=eng>.

${ }^{3}$ Para mais informações, acesse: https://smu.ca/about/welcome.html

${ }^{4}$ Para mais informações, acesse: https://www.halifax.ca/about-halifax
} 